Volume 13

Issue 1. A barrier-free health system for Indigenous Communities

Article 3

DOI:https;//doi.org/10.18357/ijih.v13i1.30279

August 2018

\title{
Understanding the Sleep Habits of Children Within an Indigenous Community.
}

\section{Richard B. Hovey}

Division of Oral Health and Society, Faculty of Dentistry, McGill University, Montreal, Quebec, Canada and

Kahnawake Schools Diabetes Prevention Project (KSDPP), Kahnawake, Quebec, Canada

Evangeline Seganathy

Department of Family Medicine, McGill University, Montreal, Quebec, Canada

Angela C. Morck

Morgan Phillips

Kahnawake Schools Diabetes Prevention Project (KSDPP), Kahnawake, Quebec, Canada

Adriana Poulette

Kahnawake Schools Diabetes Prevention Project (KSDPP), Kahnawake, Quebec, Canada

Morrison King

Kahnawake Schools Diabetes Prevention Project (KSDPP), Kahnawake, Quebec, Canada

Ann C. Macaulay

Department of Family Medicine, McGill University, Montreal, Quebec, Canada and

Kahnawake Schools Diabetes Prevention Project (KSDPP), Kahnawake, Quebec, Canada

Reut Gruber

Department of Psychiatry, McGill University; Attention Behaviour and Sleep Laboratory, Douglas Mental Health University Institute, Montreal, Quebec, Canada

Follow the International Journal of Indigenous Health at:

https://jps.library.utoronto.ca/index.php/ijih/index

\section{Recommended Citation:}

Hovey, R. B., Seganathy, E., Morck, A., Phillips, M., Poulette, A., King, M., Macaulay, A. C., \& Gruber, R. (2018). Understanding the sleep habits of children within an Indigenous community. IJIH, 13(1), $42-64$.

https;//doi.org/10.18357/ijih.v13i1.30279 


\title{
Understanding the Sleep Habits of Children Within an Indigenous Community.
}

\begin{abstract}
This study was developed within the participatory research framework of a diabetes prevention project to understand the meaning of sleep and sleep habits of Indigenous preschool and elementary school children. Sleep deprivation is a known risk factor for obesity and Type 2 diabetes. A philosophical hermeneutic approach utilized interviews and focus groups with cultural knowledge holders, Elders, parents, teachers, and school administrators. The findings reflect how Indigenous community members understood sleep through the themes of traditional ways, changing times and concerns, increasing technology, generation gaps, parental responsibility, eating habits, physical activity, and children's behaviours in school. After dissemination to the community, the findings were combined with traditional teachings and national recommendations to develop culture- and age-appropriate sleep-promoting educational materials for schools and the broader community.
\end{abstract}

\section{Keywords}

Philosophical hermeneutics, sleep habits, children, Indigenous health, school health, community-based participatory research, community.

\section{Acknowledgements}

We wish to thank the Lawson Foundation for funding "Healthier Nights for Healthier Days," Dr. Reut Gruber for providing the Actiwatches, all participants, and two Community Advisory Board members for the Kahnawake Schools Diabetes Prevention Project for reviewing this article. Evangeline Seganathy was funded by graduate student (master's degree) scholarships from Participatory Research at McGill and a McGill Internal Scholarship, and Morgan Phillips was funded by Anishnawbe Kekendazone Network Environment for Aboriginal Health Research (AK-NEAHR).

\section{Conflict of Interest}

This was not an industry-supported study. The authors declare no conflict of interest.

\section{Creative Commons Licence} (C) $\mathbb{Q} \Theta \Theta$

This work is licensed under a Creative Commons Attribution-Noncommercial-No Derivative Works 4.0 License. 


\section{Introduction}

It's easy. Dr. Martin Luther King said it ... I have a dream . . and we want you to have your own dream. Every night around ten o'clock. (Parent participant).

The objectives of this research project, undertaken by a community-based participatory research team with both Indigenous and non-Indigenous members, were (a) to gain an in-depth understanding of how sleep was interpreted within an Indigenous context, culture, and worldview, and (b) to gain information about the sleeping habits of children in the Kanien'kehàka (Mohawk) community of Kahnawà:ke, Quebec, Canada. Our intent was to combine findings from this research, community traditional knowledge, and evidence to develop culture- and age-appropriate educational materials to inform and promote healthy sleeping habits and well-being for preschool and elementary school children and their extended families.

Kahnawà:ke is part of the Mohawk Nation and the Iroquois or Haudenosaunee Confederacy, with a traditional food system based on agriculture, gathering, hunting game, and fishing that has greatly diminished in recent decades due to increasing urbanization. Today Kahnawà:ke has a population of 7,859 people (Aboriginal Affairs and Northern Development Canada, 2015). It is situated $15 \mathrm{~km}$ south of Montreal and lies in close proximity to other, non-Indigenous communities. Kahnawà:ke has a long history of independence and autonomy, with current control of many services including health, social services, and education (Bisset, Cargo, Delormier, Macaulay, \& Potvin, 2004). It also has high levels of education and employment, including many of the staff in community-controlled organizations. In 1985, and again in 2007, the prevalence of Type 2 diabetes was documented as twice as high as the Canadian rate (Horn et al., 2007; Montour \& Macaulay, 1985), although much lower than many other Indigenous communities where rates of Type 2 diabetes are 2-5 times the national rates (Young, Reading, Elias, \& O’Neil, 2000).

When the initial high prevalence of diabetes was first documented and results were shared with the community in the late 1980s, community Elders asked that "something be done" to address these high rates of disease and furthermore that efforts should focus on young children. Following this request a team from the community-controlled organizations of the hospital, social services, and the Kahnawake Education Center invited academic researchers to join the effort for their expertise in health promotion and evaluation (Macaulay et al., 2006). The resulting Kahnawake Schools Diabetes Prevention Project (KSDPP) was developed in 1994 to decrease the onset of Type 2 diabetes among present and future generations. The main objectives are to increase daily physical activity and healthy eating habits among Kahnawake children. Other important objectives are to mobilize the community, to foster community empowerment and ownership through participation in all aspects of the project and to build capacity within Kahnawake to ensure sustainability of KSDPP goals, objectives and activities in the future. (KSDPP, n.d.-a, para. 6) 
The KSDPP community-based participatory research partnership includes the research team with Indigenous and non-Indigenous researchers and the KSDPP Community Advisory Board (CAB). CAB is a coalition of volunteers from several different public service organizations within the education, recreation, health, culture, and political sectors, along with interested individuals who care about the prevention of diabetes (KSDPP, n.d.-c). University and community members work closely together guided by the KSDPP Code of Research Ethics that was jointly developed by community and university members in 1996, when development was led by an academic researcher, and in 2007, when the revisions were led by a community researcher. The KSDPP Code of Research Ethics outlines the obligations of the community and university members and guides the full team throughout all phases of the research from finalizing the research questions, deciding on data collection methods, and collecting data to interpreting preliminary findings and disseminating the results (KSDPP, 2007). Within KSDPP a Two-Eyed Seeing approach became the relational process that the researchers, both Indigenous and nonIndigenous, evolved and adopted over several years as researchers and community members learned to effectively and respectfully work together. The concept of Two-Eyed Seeing was originally developed by Mik'maw Elder Albert Marshall (Bartlett, Marshall, Marshall, \& Iwama, 2015) as a means of integrating both Indigenous and Western experiences, philosophies, and ways of knowing to promote positive relationships among researchers. It is recommended by the Institute of Indigenous Peoples' Health at the Canadian Institutes of Health Research (CIHR, 2014) and by the Institute for Integrative Science and Health (n.d.). Two-Eyed Seeing is a complex relational interaction among people who are ontologically, culturally, historically, and philosophically different but linked by their willingness to engage in a relational process toward a common horizon of understanding. A detailed description of how this process has unfolded in KSDPP can be found in an earlier KSDPP paper (Hovey, Delormier, McComber, Lévesque, \& Martin, 2017).

The vision statement of KSDPP, developed at the beginning of the project, states:

The Kahnawake Schools Diabetes Prevention Project (KSDPP) is committed to prevent type 2 diabetes in Kahnawake. We empower community members to care for their personal and family health through continual improvement of our unique diabetes prevention model based on Kanien'keha values. We collaborate with all community organizations on a shared vision of diabetes prevention activities that reach all community members.

KSDPP continues to develop our research model based on the experiences of Kahnawakero:non, staff and researchers in a partnership between Kahnawake and universities. It is shared with other Aboriginal communities and all others involved with diabetes prevention. KSDPP trains a significant number of Aboriginal people in diabetes prevention intervention and research activities. (KSDPP, n.d.-b). 
To date, numerous KSDPP school and supporting community-wide interventions have helped to increase knowledge about healthy lifestyles. The interventions include organized culturally relevant school and community events, as well as a culturally appropriate health curriculum for elementary schools delivered by teachers and developed by staff from the community hospital, KSDPP, and the elementary schools (Delormier et al., 2003; Macaulay et al., 1997). Many of these efforts include the promotion of traditional foods (Murdoch-Flowers et al., 2017). Community ecological changes, such as only healthy foods at the youth centre and a new walking path, provide increased opportunities for children and their families to eat healthily and be physically active. In partnership with the community elementary schools, KSDPP has also helped to develop school-based wellness policies promoting healthy eating and increased physical activity (Hogan et al., 2014; Macridis et al., 2016). All these endeavours contribute to building knowledge, skills, and capacity and promoting empowerment, wellness, and ownership (Cargo, Delormier, Lévesque, McComber, \& Macauley, 2011; Salsberg, Macridis, Garcia Bengoechea, Macaulay, \& Moore, 2017) as recommended by the Truth and Reconciliation Commission of Canada (2015) and the UN Declaration on the Rights of Indigenous Peoples (United Nations, 2008).

\section{Why Sleep Matters}

Recent evidence demonstrates that both adults and children with shortened sleep are at increased risk of developing obesity (Chaput et al., 2011; Chaput \& Tremblay, 2012; Taveras, Gillman, Pena, Redline, \& Rifas-Shiman, 2014), which is a major risk factor for developing diabetes. In a project with children aged 5-10 years, it was shown from parental reported questionnaires that shortened sleep was the most important risk factor for being overweight and obese when compared to other contributing factors such as parental obesity, greater than three hours of television viewing, and physical inactivity (Chaput, Brunet, \& Tremblay, 2006). A meta-analysis of 11 longitudinal studies, comprising 24,821 participants, revealed that subjects sleeping for short duration had twice the risk of being overweight or obese, compared with subjects sleeping for long duration (Fatima, Doi, \& Mamun, 2015). In adults shortened sleep is also an independent risk factor for developing Type 2 diabetes (McNeil, Doucet, \& Chaput, 2013; Reutrakul \& Van Cauter, 2014).

Risk factors for shortened sleep in children include presence and use of electronic media in their bedrooms (Cespedes et al., 2014; Chahal, Fung, Kuhle, \& Veugelers, 2013). One study found that having a bedroom television is associated with weight gain beyond the effect of television viewing time, a finding that "could be the result of uncaptured effects of television viewing or of disrupted sleep patterns" (Gilbert-Diamond, Li, Adachi-Mejia, McClure, \& Sargent, 2014). Another cause of shortened sleep in children is excess daytime caffeine intake (Calamaro, Yang, Ratcliffe, \& Chasens, 2012; Warzak, Evans, Floress, Gross, \& Stoolman, 2011). 


\section{Study Design}

\section{Methodology}

Because of the above evidence linking sleep deprivation with increased obesity in children, and obesity and Type 2 diabetes in adults, KSDPP researchers and CAB members together decided that KSDPP should consider promoting healthy sleeping habits in addition to their long-standing promotion of healthy eating and increased physical activity. The overall KSDPP team also decided that it was important to first ask community members about their insights into sleep and to evaluate the actual sleep habits of both preschool and elementary school children. This background information was especially important as we could find only one other article from Canada evaluating the impact of electronic media on sleep duration for Indigenous youth ages 10-15 (Gates, Hanning, Martin, Gates, \& Tsuji, 2013) and none about sleeping habits of young Indigenous children. Our main goal was to use the findings from this study to contribute to the development of culturally appropriate sleep-promoting materials and new interventions for community members, school staff, and young schoolchildren. This idea was then discussed with the Kahnawake Education Center, Elders, and principals and teachers of the preschool and elementary schools, who were all supportive of the proposal.

In 2012, with this community support, the community-academic KSDPP team wrote a successful research grant proposal to undertake a study that consisted of two phases. Phase 1 consisted of gathering information from community Elders, cultural knowledge holders, parents, teachers, and school administrators about how sleep was interpreted within an Indigenous context, culture, and worldview. Phase 2 consisted of a descriptive quantitative examination of the actual sleep and sleep hygiene of young children at five Kahnawà:ke schools (Seganathy, 2014). The research questions were as follows:

1. How is sleep understood from an Indigenous perspective?

2. What are the actual sleep habits and sleep hygiene practices (e.g., use of electronic media in children's bedrooms and use of caffeine) of preschool and elementary school children in this community?

This paper offers the findings from Phase 1 with some additional results from Phase 2.

Phase 1 of this research project was guided by the philosophical hermeneutics of Hans-Georg Gadamer (Gadamer, 1989). Philosophical hermeneutic inquiry is described as the practice and theory of interpretation and understanding in human contexts and has been shown to have invaluable applied utility that has been well documented within healthcare research (Hovey et. al., 2017; Moules, McCaffrey, Field, \& Laing, 2015). It involves an exploration into human experience (Davey, 2006; Gadamer, 1989), and philosophical hermeneutic researchers' intentions are to gain insight and understanding through the ways in which individual participants, as well as participants as a collective, make sense of their experiences with regard to a shared topic (Hovey, Delormier, \& McComber, 2014). Self-reflection, including recognizing and acknowledging one's assumptions and biases with a thorough 
understanding, and consistent application of the philosophy make up the rigorous elements in philosophical hermeneutic data analysis. Interviewing, transcribing, listening to audio recordings, and grouping similar interview excerpts familiarize the researchers with the data and facilitate the development of "findings" that address the research question (Moules et al., 2015).

\section{Participant Recruitment}

Ethics approval was obtained from the Kahnawà:ke Schools Combined Schools Committee (the governing body representing the schools), the school principals, the KSDPP's CAB, and McGill University's Faculty of Medicine Institutional Review Board. In Kahnawà:ke, the CAB oversees and guides all KSDPP activities, including research. Under the guidance of the KSDPP Code of Research Ethics, one of CAB's goals is to ensure that cultural and community values are upheld and protected through partnering in all grant applications, reviewing all data collection tools, interpreting preliminary results, and disseminating the findings (KSDPP, 2007).

The Indigenous research coordinator (AP), who lives in the community, first approached KSDPP staff and $\mathrm{CAB}$ members to develop a list of community Elders and cultural knowledge holders who might consent to be individually interviewed to get their perspectives and understanding about children's sleep habits. These Elders and cultural knowledge holders were from the Cultural Centre and the Longhouse whose occupations and knowledge about Haudenosaunee (People of the Longhouse) culture allowed them to comment on sleep and the importance of mythology and dreams. In accordance with CAB's mandate, it was important to begin with these Elders and cultural knowledge holders to ensure the research proceeded in a respectful, culturally appropriate manner. Eight interviews were conducted in total.

The research coordinator then approached school administrators, teachers, and parents from the four community elementary schools and the preschool, during one of the parents' days that occur two times per year. The research project was explained and invitations offered for participation in focus groups centred on how children sleep at home and its potential effect during school time on behaviour and attention. Three focus groups each consisting of between 7 and 9 participants were conducted-one each with school administrators, teachers, and parents of children attending the five schools.

Consistent with philosophical hermeneutic research, no limit was set to "power" nor was the study randomized. The number of participants in this type of research is determined by the richness of the data collected through strong exemplars about the topic of inquiry. When the topic is richly described or informed, data collection can be concluded (Moules et al., 2015).

\section{Data Generation and Analysis}

Data sources consisted of semi-structured interviews with eight individual participants, and the three focus groups with administrators, teachers, and parents. Informed consent was collected for each 
participant. Individual interviews and focus groups varied from 30 to 100 minutes and were digitally recorded. The interviews were then transcribed verbatim for ongoing analysis. Field notes were written after each interview to capture contextual details and beginning interpretations.

A research interview guided by philosophical hermeneutics is characterized by its attention to the quality of the conversation, in which the questions became an invitation for the individual participants or focus groups members to engage with the topic (Hovey et al., 2014). The interview as a conversation is important because it is the means of developing extensive discussions that interconnect understandings and perceptions. The qualitative research team comprised an external non-Indigenous researcher $(\mathrm{RH})$ and two Indigenous researchers (MP and AP).

Using a Two-Eyed Seeing approach, RH, who is an experienced philosophical hermeneutics qualitative researcher working with KSDPP for over 10 years, guided the interpretive analysis. The preliminary findings were closely reviewed in conjunction with two Indigenous researchers, including one with traditional knowledge who was also completing her $\mathrm{PhD}$ (MP) and one with her Master's degree (AP). In hermeneutics, analysis is synonymous with interpretation and occurs in the complex dialectic of research interviews with participants and interpretive memos based on the transcripts. Through this in-depth, rigorous, reflexive, and communal attention to the data, the team collaboratively establishes the most relevant findings. Throughout the research, as with all KSDPP research projects, the research team presented regular updates about the research process, data collection activities, any challenges, and preliminary findings for discussion with the KSDPP CAB at their monthly meetings.

\section{Results / Findings}

The interviewees provided rich, in-depth accounts of how people in Kahnawà:ke view sleep and reflected on traditional ways; changing environments and the current way of living; facilitators and distractions to sleep, including technology in the bedrooms; and how sleep or a lack of sleep affects school and home participation of school-aged children (Hovey et al., 2014). The findings showed that a typical day in the life of a child may include attending school, homework, socializing, playing games, extracurricular activities, sports, and family expectations, constituting a busy life for students, parents, and grandparents.

The initially interviewed Elders and cultural knowledge holders shared that while dreams, and the interpretation of dreams, had a significant presence within the community-sleep was still sleep. In other words, understanding the sleep habits of children could be done without attention to dreams as a mitigating or culturally relevant factor. 


\section{The World Has Shifted}

The world has shifted from watching the sun and watching the moon come up compared to putting on the light, putting on the computer, putting on TV, putting on movies, so they're distracted by all those things. (Elder participant).

The shifting world progresses and alters the way we perceive, watch time, and interact with our world. Only a few generations ago we depended upon the rhythms of the days, months, and seasons where the timekeepers telling us when to wake up and to go to bed. This way of life has faded away gradually and has been replaced with the technological interfaces that mediate our way of being with the world. The interface has changed dramatically the relationship human beings have with sleep and timing of when and how. The first finding from the research interviews directed our attention to the possibility that children were not achieving adequate sleep because of the negative influence of technology. This was especially true for children who had access to technologies in their bedrooms.

So what she sees with that, some of the kids come in and they're really tired and she'll ask what is going on and they'll say "oh I stayed on my PlayStation until 2 in the morning." Well, what were you doing up at 2 in the morning? . . "I just didn't listen. I just kept playing anyway." (Teacher participant).

Parents, teachers, and administrators all pointed to the late-night use of cell phones, computers, televisions, and video games as reasons for the sleep deprivation they are witnessing with children. The use of these devices is a relatively new phenomenon; the generation before just had a family TV and a family phone and monitoring the use of these was simple compared to today.

In the Grade 6 classroom, I notice that the kids are 75\% sleep deprived because they may have to go into their rooms at like 9 o'clock but they have access to the internet or their phones, music, and you name it. (School administrator participant).

Several participants identified children having access to technology in the bedroom as a particular problem, as it allowed them to stay up late with or without their parents' knowledge.

The other one was the same issue as the screens, how to monitor the screens, to take the screens out of the bedroom and centralize places in the house because once they're in the bedroom it's hard to control, it's hard to monitor, it's hard to see what they're playing, it's hard to see how long they're playing it. (Parent participant).

Technology in the bedroom was thought to make it more difficult to monitor and control what children are watching or playing, and how late at night they were staying awake. Some participants also 
mentioned one negative impact the overuse of technology had on the imagination of children and their motivation to go outside, play, and be active. Several participants stated they did not allow televisions in their child's room, maintaining that it created a more conducive sleep environment for the child to go to bed at a reasonable hour and get a more restful sleep.

Another participant spoke about their worry about children developing their imagination and creativity: "The biggest thing I see is that they have, they are being deprived of an imagination. They are given everything, there is no imagination left." (Elder participant). This was supported by another participant who said, "In the long run . . . 'cause all their life they want to be entertained, entertained, entertained. Now there's just too much distraction. Everybody has TVs." (Parent participant). The loss of imagination means to become dependent on the thinking of others; creativity becomes limited by technological interpretations of the games we play, rather than games we invent, organize, and modify. The loss of imagination seems to be part of a cycle whereby children play games or watch screens (being entertained), which can keep them up late at night, and when they go to school their fatigue limits their capacity to imagine and be creative. The natural colours of the sun rising and setting are replaced by the artificial hues of computer screens and other devices.

Without imagination we lose the possibility of creating new ways of expression, negatively affecting art, culture, and intellectual curiosity and ways to solve life's challenges.

\section{Parental Responsibility}

Generally, my kids get 9 to 10 hours of sleep. They don't have any health problems or anything. I make them go to bed at like 9 o'clock. I shut the TV off, they don't have a TV in their room, and I shut everything off and they get in bed. (Parent participant).

Another area often discussed in conjunction with technology, albeit controversial, was an absence of proper parenting.

We tell them they have to ... what time did you go to bed? Some of them say that they have TVs in their rooms, their bedrooms. Ah, a lot of technology in the bedrooms. Parents let them stay up late. (Teacher participant).

This was a very sensitive issue but was pervasive throughout the interviews. One participant (parent) shared, "It is the parents who need the education, more than the kids. Because at this point they are the ones in control of the house." Several participants believed it was up to the parents - "change has to be at home as well" - to ensure their children were achieving adequate sleep, and held the parents responsible for the sleep deprivation experienced by some children at school. 
In school, I notice that a lot of the children are not sleeping as much as they should.

They're coming in and talking about shows that they watched and I know they're on at 10 o'clock. . some later. (Teacher participant).

Various parents were viewed as not setting appropriate limits for their children and allowing them to stay up late playing video games, talking on phones, or watching television. Several of the participants considered it the responsibility of the parents to better manage the household, and to set a good example for their children.

But actually, for me, that's what has to happen. . . we need to get the kids healthy ... mind, body, the parents need to become more involved, more responsible. (Parent participant).

The issue of being part of a blended family was also cited as being a possible disruption of home life, with the need to define or co-create "between homes" an adequate structure for their children. Children experience inconsistencies of living within two families, each possibly with their own interpretation of how children and sleep should be addressed and monitored.

\section{Kids Have Great Thumbs Now}

All you have is your brain, and outside... you don't have the toys, you don't have all that, you make up your own things. And our brain was continually working; all of our brain was working, not another brain working for us. Come the end of the day and you've had it. You are in bed and you are out like a light. (Elder participant).

Participants also discussed how the lack of outdoor physical activity was a significant contributing factor to children not acquiring adequate hours and quality of sleep.

And you've got to be tired. So, if you're bored or you haven't done anything all day, you're not going to sleep well because you haven't wasted enough energy to be tired . . that's where physical activity comes in. (Elder participant).

These participants felt that children staying inside all day playing video games and watching television led to their becoming more physically inactive, which negatively affected their sleep patterns.

Not anymore ... you don't even see the road hockey game like before. . . I think the change, the big thing has been the computer, and the video games... kids have great thumbs now. (Elder participant). 
Participants acknowledged the importance of feeling and being physically tired (from exercise) in order to get a good night's sleep.

Yeah, we weren't in the house all day like these kids. . . How many kids are actually out playing now on their own besides organized sports, and that has a direct effect on their sleep. (Elder participant).

One person explained what helped their son become tired and sleep better:

I noticed that on certain days he was great because [he'd had] a full night's sleep. And I was like, what are you doing with him to make him sleep? She said, "I make him run around the block." (Parent participant).

Another parent observed the lack of children playing outside "like we used to" as having a direct adverse effect on their quality and duration of sleep, "because people when they're tired . . . are very, very motivated to sleep."

\section{Because the Food ...}

We're a boring house because you know lots of families have that . . cupboard full of goodies . . . and we don't have that, there's nothing yummy to eat in the house. . . Anyway, if there was junk, they would have totally ate it . . like chips or cookies or whatever... and then go to sleep with a full belly full of this crap. Instead they're coming up and they're having an apple. . that's why none of them have any weight problems. It's true. So yeah, get rid of the cupboard and you can sleep. (Parent participant).

Several participants brought into the conversation the importance of proper nutrition, and the negative impact that junk food has on a child's sleep.

Because the food... what they're taking in during the day also has an adverse effect on their sleeping. ... My son will eat toast with jam on it, Eggo waffles or he'll have Sugar Crisp. (Parent participant).

They explained that more and more people are eating a diet full of processed foods, or "junk foods," saying that our bodies are ill equipped to digest these kinds of foods, which are high in salt, fat, and caffeine. As a result, our bodies are unable to rest easily and therefore are stimulated by the digestion of junk foods. Many participants commented on the importance of having a healthy breakfast and lunch, and how that can help children do better in school: "And it's all connected, you know ... physical education, eating, sleeping" (Parent participant). The processed food has replaced the traditional ways of 
eating that were part of being connected to the land, water, and earth. "You have to look at the thing that it's easier to buy processed food in the package than actual healthy food" (Parent participant). This balance did not separate the person from a way of eating that promoted sleep, health and well-being.

The sleep and the food went together, they call it country food . . they had better sleeping habits than people who ate frozen pizza, fries because it's digested differently and so the body is resting differently. Or even late-night snacking, if you're snacking while you're looking at a screen, it's different than if you're having a meal with your family. Once lunchtime comes around or even snack time mid-morning, they open up their lunch box and there are all kinds of junk in there. So that might give them a little bit of energy boost but then as they get that high, they crash by the time lunchtime comes along. (School administrator participant).

Sleep and food are intertwined. "Country food" refers to a modality of eating food that is not processed but rather grown in local gardens or wild harvested with care and prepared in a way that nourishes the body. Country food speaks of not only the food itself, but also a way of being together as a family, where the events, concerns, and joys of the day are shared, processed, and addressed.

\section{Generation Gaps and Changing Times}

And as much as I love being able to go on my iPad and get a menu or talk to someone on the other side of the world, those conveniences that we appreciate, it's their normal. And it's made them a different generation. (Parent participant).

Many knowledge holders within the community perceived there to be a disconnection among community Elders, young parents, and the current generation, the children.

Before the bridge and everything came in, we were very active, we were always at the water, we were very community oriented, very family oriented; things have changed in the last 20 years. (Elder participant).

They believed this generational gap was leading to the adoption of a more Westernized perspective and the loss of cultural and family traditions. "I always slept with my mom, up until the time I was a teenager. All of us always slept with my mom. . that's how I raised my kids" (Parent participant). Several interviews and group discussions testified to the importance of learning from previous generations and valuing the knowledge that Elders possess. When the image on a screen replaces the imagination of a child there is a loss of learning to play, work, and interact with others. 
There's no imagination anymore .. . I remember when you were a kid, lunch is over and you would go and come back for supper, come back at dark. And you didn't have anything and you made your own fun. They don't do that now. If you threw a bunch of kids outside and you threw a bat, a ball, and a whole bunch of stuff . . I don't think some kids could even put together a pick-up game because they are always waiting for somebody to run it and organize it and set it up. (Elder participant).

Another participant spoke about how they observed that people within the community were working toward regaining a more wholistic way of life. This is a way of living that does not ignore the "old ways" but brings them into relevance within their lives (Hovey et al., 2014).

Younger people are going back to traditions and trying to go back to natural foods, healthier foods, organic ... to be healthy and green, so and people are listening and understanding that there's a change coming. The world is changing . . they understand that we have to go back more towards our old ways because it was simpler. (Elder participant).

However, another participant spoke of the need for the younger generation to carry on the traditions but observed that children cannot be forced to care in a more meaningful way.

Because I see that today with some of the young parents in the Longhouse, they grab their kid and they sit them here and they have to sit and have to listen because they're the ones that have to carry this on. If they're not listening, then it's going to be lost. (Parent participant).

The old ways are not just about how life used to be. There is recognition that returning to past ways of living a simpler life are more difficult given the influx of technology. While an ever-changing world may be beyond our control, the values, culture, and traditions that are foundational to this community need to be listened and interpreted into this new context of living or they will be lost.

\section{Reflections Past and Present}

Another finding within the individual interviews was the referencing of children's behavioural changes as a personal reflection when compared to two or even three generations ago.

So I was amongst the children and I could see the differences from when my children were. . you know when they were small and in school, I found it a big difference and I had a very hard time and having to cope with children who do not. . . it's like they can't hold their attention, you know? (Teacher participant). 
One school volunteer, a grandparent, made the decision to stop volunteering because she found it difficult to cope with a new generation's behaviour.

They want to stay up all night or sleep all day. There's a time to be sleeping and it's night and being awake during the day because of the, I guess you would say of the natural order, most humans are supposed to be sleeping, I mean you're supposed to be sleeping at night and up at the crack of dawn. That's what the stories are in the opening, that the birds when they start singing, that's when you're supposed to start getting up . . that's the opening prayer that everybody learns and that comes from the Creation Story. (Elder participant).

Two or three generations ago, children were more physically active outdoors, to the point where they were so exhausted at the end of the day, sleep time was welcomed. Children spent more time with grandparents, who taught about eating well and "taking care of yourself" through adequate rest. It was mentioned that the economy was much different_- "we were all poor." Another said, "We all had gardens and chores ... all of these things kept us occupied and literally tired us out." Another sign of changing times, as articulated in one interview, was that not too long ago, most pregnant women were not in the workforce and therefore spent more time at home learning about how to be wholistically well during pregnancy. In the past, mothers and grandmothers would teach expectant mothers about proper practices of care for themselves when pregnant. These teachings retained the connection to the creation story; the voice of mother to daughter, grandparents to grandchildren kept the stories alive as they were carefully and purposefully passed on to the next generation. This personal family connection not only served to pass on knowledge, traditions, and culture, but also promoted and strengthened relationships.

In another interview, a teacher spoke at length about how we live very differently, stating that the children of today "want to stay up late and sleep during the day." Part of the cultural relevance of the "Thanksgiving Address" was being up early to recite it each morning; one parent said it would be recited "when the birds start singing." This is difficult when children cannot wake up early to welcome the new day. Gadamer (1996) wrote:

The mystery of sleep seems to me to be one of those fundamental experiences in which our human self-understanding reveals itself both as something continuous with nature and yet as something which constantly strives towards establishing the new. Every morning of every day each of us experiences the promise and the risk involved in a new day and a new morrow. It is precisely here, in the movement between sleep and waking, between relaxation and exertion, that we encounter the particular constitution of human beings, their capacity to abandon themselves to the pursuit of the most daring goals while retaining their own self-identity. (pp. 85-86). 
Gadamer reminds us of the potential found in and through sleep, not only as a health benefit, but also its effect on imagination, physical activity, and self-identity. Although we cannot return to the times of our parents and grandparents, we can retain their messages, values, beliefs, and wisdom through a reinterpretation first imagined and then practised in a modern context.

\section{Discussion}

Parents, Elders, and cultural knowledge holders were aware that a lack of sleep was affecting how well their children were doing in school, both academically and behaviourally. For example, several parents mentioned that their child's teachers had phoned with complaints about inattentiveness, misbehaving, grouchiness, and fatigue. The majority of parents agreed that televisions, cell phones, and video games were among the greatest distractions for their children. Some parents said they did not always know when their child was asleep; having a television, computer, or video game device in the bedroom encouraged children to stay up late into the night and sometimes the early morning.

In general, parents were receptive to the idea of introducing a sleep curriculum into the schools. However, they were concerned about whether it would become more homework for their children. Other parents thought this could be a great way to build up self-esteem and self-efficacy in the childrenthrough knowledge. The parents also felt that it would help them within their family dynamic to make informed decisions as parents with other family members if the schools provided this information. They also expressed that children may feel empowered through sharing knowledge about sleep being essential for success.

Teachers have noticed an increase during the past few years in the number and frequency of students falling asleep at their desks, unable to do their work, and being "grouchy" and "hypersensitive" - all of which may be attributed to a lack of sleep. Several teachers mentioned that parents were not setting proper time limits with their children and were letting them stay up late into the night or even into the early morning because of electronic media or televisions in their bedroom. This could explain why some of the children are "really tired" in school, as even moderate amounts of sleep loss (30 to 60 minutes) can be cumulative and can have a significant negative impact on alertness and cognitive learning (Gruber et al., 2012). Teachers supported the importance of children participating in daily physical activity to feel physically and healthily tired. Overall, teachers were receptive to incorporating sleep materials into the current health curriculum, although concerned it should not become onerous.

Administrators, as did the parents and teachers, shared a concern for the negative influence of having a television and/or electronic media located within the child's bedroom. They also spoke to the lack of proper sleep schedules, unstable routines, and lax parenting habits as reasons why children were not achieving adequate sleep. The emphasis among administrators was on the importance of parental 
involvement. They asserted that since parents are in control of the house and also needed the sleep education. Administrators were receptive to the possibility of a curriculum on sleep, provided that it could be flexibly integrated into existing subjects.

The home activities that are keeping elementary school children awake in Kahnawake are not uniquely different from those for children in other communities, and the parent, teacher, and administrative focus groups all expressed that a lack of sleep had an effect on school performance, participation in other activities, and family life. Other studies show that children are sleeping less than previous generations (Matricciani, Olds, \& Petkov, 2012), and that many children have electronic media in their bedrooms and are using technology late at night (Chahal et al., 2013), resulting in later sleep onset (Foley et al., 2015) which adversely affects sleep duration (Cain \& Gradisar, 2010).

In terms of sleep hygiene practices, our findings from Phase 2 supported the concerns of those who were interviewed, as half of children age 3-5 and almost three quarters of those age 6-12 have TVs and other electronic media in their bedrooms and many are using them past their bedtimes (Seganathy, 2014). The Canadian Pediatric Society recommends children do not have TVs in their bedrooms and also recommends limiting screen time for children to 2 hours per 24 hours (Lipnowski \& LeBlanc, 2012); however, many children are exceeding this recommendation past their bedtimes (Seganathy, 2014). Televisions in children's bedroom have also been associated with gaining excess body weight (Chahal et al., 2013), putting children at risk for obesity and Type 2 diabetes later in life. Conversely, increased sleep duration results in lower reported food intake and lower body weight (Hart et al., 2013). The caffeine intake reported in this study is within the amount allowed by Health Canada (2012) for these age groups, so this is not a concern (Seganathy, 2014). The updated information on consumption of iced tea and soft drinks is very useful information for KSDPP intervention staff. KSDPP has always emphasized that these drinks contain high amounts of sugars and therefore will continue to recommend that children drink water, milk, and small amounts of fruit juices.

\section{Limitations}

Fundamentally, the concept of limitations in research is a quantitative construct that is not completely transferable to qualitative research, in particular for philosophically based research such as hermeneutics and phenomenology. However, the ability to conduct rigorous qualitative research is found in the academic training and lived experiences of the Indigenous and non-Indigenous qualitative researchers. This translates to how well the researchers understand the philosophical foundations of the research approach, generate purposeful questions, and interpret the narrative data. A Two-Eyed Seeing approach helped us to develop a common understanding, language, and commitment among the researchers and community toward completing this research project. Based on these criteria and because of the numerous discussions with community Indigenous researchers and CAB we believe we asked the right questions, the right way, to the right groups of research participants who best informed the 
intention of this study. Certainly, what we learned from this study did generate more potential research questions, but this is not a limitation but rather how qualitative research works.

For the second phase, after informing the community through the local media and working with the teachers about the reasons for collecting information on children's sleeping habits, we sent home questionnaires with the children to the parents of preschool and elementary school children, because this approach has worked well for previous KSDPP data collections. The questionnaires had all been reviewed by $\mathrm{CAB}$ members and included information as to how parents could contact the Indigenous research coordinator if they had any questions. The questionnaires asked about the presence of electronic media in children's bedrooms and use after bedtime, and soft drink intake. Only $24 \%$ of parents of preschool children and $12 \%$ of parents of elementary school children answered the questionnaires, and we cannot tell if the responses are representative of children living in the community. CAB members who reviewed the results believe this low response rate was due to parents being overwhelmed with three KSDPP requests at the same time. After detailed internal KSDPP discussion, this bundling had been an attempt to minimize paperwork for parents, but we believe it failed because it overwhelmed the parents by presenting them with three different research questionnaires at the same time within one research package.

\section{Conclusion}

To our knowledge this is the first research project to evaluate sleep for Indigenous preschool and elementary school children. Given the importance of healthy sleeping habits to overall health and academic learning, we hope that others will undertake similar studies. These results have been widely disseminated within Kahnawà:ke, through the local newspaper and radio station and community presentations. Through the co-development and adoption of a Two-Eyed Seeing approach, all voicesIndigenous and non-Indigenous - were valued contributions to this research. This process of working together began several years before this study was conducted, with the relationship among the researchers already well established. This relationship facilitated working on this study because we had already had time to learn deeply from each other (Hovey et al., 2017).

Since finalizing data collection, a team of KSDPP intervention staff, cultural knowledge holders, community artists, curriculum developers, and KSDPP research team sleep experts have combined their skills, traditional knowledge, these results, and national recommendations to finalize a culture- and ageappropriate sleep-promoting curriculum. The curriculum, with associated lesson plans for Grades 1-6, will promote healthy sleeping habits in the preschool and elementary schools and supply educational materials for the entire community. All materials were discussed in detail with the Kahnawake Education Center and staff of all the elementary schools and the preschool. The Indigenous research coordinator has been invited by participating schools to present on healthy sleep habits to parents at the welcoming and information sessions. The same team also developed a book that follows the life of a family in traditional times and shows how sleep was an integral component of daily life and is now 
finalizing a book that follows a modern family living today. The first book was launched by one of the Indigenous researchers through a reading to elementary school children and their parents at the Kahnawà:ke community library, and copies written in both Mohawk and English have been donated to the library and the schools. The books will also be given to all parents who participated in the study.

Our research has revealed that a successful intervention for sleep must include parents, teachers, school administrators, and the support of the community. Otherwise a fragmented intervention will fail to provide a cohesive approach to improve sleep hygiene and achieve adequate sleep for children in Kahnawà:ke or elsewhere. We believe that undertaking this research project has increased community knowledge about the importance of sleep, and the resulting interventions to promote healthy sleeping will contribute to community empowerment and decreased rates of Type 2 diabetes.

\section{References}

Aboriginal Affairs and Northern Development Canada. (2015). The Nations. Retrieved from https://www.aadnc-aandc.gc.ca/Mobile/Nations/profile_kahnawake-eng.html

Bartlett, C., Marshall, M., Marshall, A., \& Iwama, M. (2015). Integrative science and Two-Eyed Seeing: Enriching the discussion framework for healthy communities. In L. K. Hallstrom, N. P. Guehlstorf, \& M. W. Parkes (Eds.), Ecosystems, society and health: Pathways through diversity, convergence and integration (pp. 280-326). Montreal, QC: McGill-Queen's University Press.

Bisset, S., Cargo, M., Delormier, T., Macaulay, A. C., \& Potvin, L. (2004). Legitimizing diabetes as a community health issue: A case analysis of an Aboriginal community in Canada. Health Promotion International, (19)3, 317-326. https://doi.org/:10.1093/heapro/dah305

Cain, N., \& Gradisar, M. (2010). Electronic media use and sleep in school-aged children and adolescents: A review. Sleep Medicine, 11(8), 735-742.

https://doi.org/10.1016/j.sleep.2010.02.006

Calamaro, C. J., Yang, K., Ratcliffe, S., \& Chasens, E. R. (2012). Wired at a young age: The effect of caffeine and technology on sleep duration and body mass index in school-aged children. Journal of Pediatric Health Care, 26(4), 276-282. https://doi.org/10.1016/j.pedhc.2010.12.002

Canadian Institutes of Health Research [CIHR]. (2014). CIHR Institute of Aboriginal Peoples' Health strategic plan 2014-18. Retrieved from http://www.cihr-irsc.gc.ca/e/49589.html\#section_5_2

Cargo, M. D., Delormier, T., Lévesque, L., McComber, A. M., \& Macaulay, A. C. (2011). Community capacity as an "inside job": Evolution of perceived ownership within a university-Aboriginal community partnership. American Journal of Health Promotion, 26(2), 96-100.

https://doi.org/10.4278/ajhp.091229-ARB-403

Cespedes, E. M., Gillman, M. W., Kleinman, K., Rifas-Shiman, S. L., Redline, S., \& Taveras, E. M. (2014). Television viewing, bedroom television, and sleep duration from infancy to mid-childhood. Pediatrics, 133(5), e1163-e1171. https://doi.org/10.1542/peds.2013-3998

Chahal, H., Fung, C., Kuhle, S., \& Veugelers, P. J. (2013). Availability and night-time use of electronic entertainment and communication devices are associated with short sleep duration and obesity 
among Canadian children. Pediatric Obesity, 8(1), 42-51. https://doi.org/10.1111/j.20476310.2012.00085.x

Chaput, J.-P., Brunet, M., \& Tremblay, A. (2006). Relationship between short sleeping hours and childhood overweight/obesity: Results from the 'Québec en Forme' Project. International Journal of Obesity, 30(7), 1080-1085. https://doi.org/10.1038/sj.ijo.0803291

Chaput, J.-P., Lambert, M., Gray-Donald, K., McGrath, J. J., Tremblay, M. S., O’Loughlin, J., \& Tremblay, A. (2011). Short sleep duration is independently associated with overweight and obesity in Quebec children. Canadian Journal of Public Health, 102(5), 369-374.

https://doi.org/10.17269/cjph.102.2749

Chaput, J.-P., \& Tremblay, A. (2012). Insufficient sleep as a contributor to weight gain: An update. Current Obesity Reports, 1(4), 245-256. https://doi.org/10.1007/s13679-012-0026-7

Davey, N. (2006). Unquiet understanding: Gadamer's philosophical hermeneutics. Albany: State University of New York Press.

Delormier, T., Cargo, M., Kirby, R., McComber, A., Rice, J., \& Potvin, L. (2003). Activity implementation as a reflection of living in balance: The Kahnawake Schools Diabetes Prevention Project. Pimatisiwin: A Journal of Aboriginal and Indigenous Community Health, 1(1), 145-163.

Fatima, Y., Doi, S. A. R., \& Mamun, A. A. (2015). Longitudinal impact of sleep on overweight and obesity in children and adolescents: A systematic review and bias-adjusted meta-analysis. Obesity Reviews, 16(2), 137-149. https://doi.org/10.1111/obr.12245

Foley, L. S., Maddison, R., Jiang, Y., Marsh, S., Olds, T., \& Ridley, K. (2013). Presleep activities and time of sleep onset in children. Pediatrics, 131(2), 276-282. https://doi.org/10.1542/peds.2012$\underline{1651}$

Gadamer, H. G. (1989). Truth and method (2nd ed.; J. Weinsheimer \& D. G. Marshal, Trans.). New York, NY: Continuum.

Gadamer, H. G. (1996). The enigma of health: The art of healing in a scientific age. (J. Gaiger \& N. Walker, Trans.). Stanford, CA: Stanford University Press.

Gates, M., Hanning, R. M., Martin, I. D., Gates, A., \& Tsuji, L. J. S. (2013). Body mass index of First Nations youth in Ontario, Canada: Influence of sleep and screen time. Rural and Remote Health, 13(3), 2498. Retrieved from http://www.rrh.org.au

Gilbert-Diamond, D., Li, Z., Adachi-Mejia, A. M., McClure, A. C., \& Sargent, J. D. (2014). Association of a television in the bedroom with increased adiposity gain in a nationally representative sample of children and adolescents. JAMA Pediatrics, 168(5), 427-434.

https://doi.org/10.1001/jamapediatrics.2013.3921

Gruber, R., Michaelsen, S., Bergmame, L., Frenette, S., Bruni, O., Fontil, L., \& Carrier, J. (2012). Short sleep duration is associated with teacher-reported inattention and cognitive problems in healthy school-aged children. Journal of Nature and Science of Sleep, 4(1), 33-40.

https://doi.org/10.2147/NSS.S24607 
Hart, C. N., Carskadon, M. A., Considine, R. V., Fava, J. L., Lawton, J., Raynor, H. A., . . Wing, R. (2013). Changes in children's sleep duration on food intake, weight and leptin. Pediatrics, 132(6), e1473-e1480. https://doi.org/10.1542/peds.2013-1274

Health Canada. (2012). Caffeine in food. Retrieved from http://www.hc-sc.gc.ca/fnan/securit/addit/caf/food-caf-aliments-eng.php

Hogan, L., Bengoechea, E. G., Salsberg, J., Jacobs, J., King, M., \& Macaulay, A. C. (2014). Using a participatory approach to the development of a school-based physical activity policy in an Indigenous community. Journal of School Health, 84(12), 786-792. https://doi.org/10.1111/josh.12214

Horn, O. K., Jacobs-Whyte, H., Ing, A., Bruegl, A., Paradis, G., \& Macaulay, A. C. (2007). Incidence and prevalence of Type 2 diabetes in the First Nation community of Kahnawa:ke, Quebec, Canada, 1986-2003. Canadian Journal of Public Health, 98(6), 438-443.

Hovey, R. B., Delormier, T., \& McComber, A. (2014). Social-relational understandings of health and well-being from an Indigenous perspective. International Journal of Indigenous Health, 10(1), 3554. https://doi.org/10.18357/ijih.101201513195

Hovey, R. B., Delormier, T., McComber, A. M., Lévesque, L., \& Martin, D. (2017). Enhancing Indigenous health promotion research through Two-Eyed Seeing: A hermeneutic relational process. Qualitative Health Research, 27(9), 1278-1287. https://doi.org/10.1177/1049732317697948

Hyde, M., O’Driscoll, D. M., Binette, S., Galang, C., Tan, S. K., Verginis, N., . . Horne, R. S. C. (2007). Validation of actigraphy for determining sleep and wake in children with sleep disordered breathing. Journal of Sleep Research, 16(2), 213-216. https://doi.org/10.1111/j.13652869.2007.00588.x

Institute for Integrative Science and Health. (n.d.). Two-Eyed Seeing. Retrieved from http://www.integrativescience.ca/Principles/TwoEyedSeeing/

James, E. J., Kristjánsson, A. L., \& Sigfúsdóttir, I. D. (2011). Adolescent substance use, sleep, and academic achievement: Evidence of harm due to caffeine. Journal of Adolescence, 34(4), 665-673. https://doi.org/10.1016/j.adolescence.2010.09.006

Kahnawake Schools Diabetes Prevention Project [KSDPP]. (n.d.-a). About KSDPP and Kahnawake [Section of web page]. Retrieved from https://www.ksdpp.org/elder/about_ksdpp.php

Kahnawake Schools Diabetes Prevention Project [KSDPP]. (n.d.-b). The vision of KSDPP [Section of web page]. Retrieved from https://www.ksdpp.org/elder/about_ksdpp.php

Kahnawake Schools Diabetes Prevention Project [KSDPP]. (n.d.-c). What is CAB? [Web page]. Retrieved from https://www.ksdpp.org/elder/cab.php

Kahnawake Schools Diabetes Prevention Project [KSDPP]. (2007). Code of research ethics. Retrieved from https://www.ksdpp.org/media/ksdpp_code_of_research_ethics2007.pdf

Lipnowski, S., \& LeBlanc, C. M. A. (2012). Healthy active living: Physical activity guidelines for children and adolescents [Canadian Paediatric Society position statement]. Paediatrics \& Child Health, 17(4), 209-210.

Macaulay, A. C., Cargo, M., Delormier, T., Lévesque, L., Bisset, S., \& Potvin, L. (2006). 
Kanien'kehá:ka (Mohawk) ways for the primary prevention of Type 2 diabetes: The Kahnawake Schools Diabetes Prevention Project. In M. L. Ferreira \& G. C. Lang (Eds.), Indigenous Peoples and diabetes: Community empowerment and wellness (pp. 407-433). Durham, NC: Carolina Academic Press.

Macaulay, A. C., Paradis, G., Potvin, L., Cross, E. J., Saad-Haddad, C., McComber, A., . . Rivard, M. (1997). The Kahnawake Schools Diabetes Prevention Project: Intervention, evaluation, and baseline results of a diabetes primary prevention program with a native community in Canada. Prevention Medicine, 26(6), 779-790. https://doi.org/10.1006/pmed.1997.0241

Macridis, S., García Bengoechea, E., McComber, A. M., Jacobs, J., Macaulay, A. C., \& Members of the Kahnawake Schools Diabetes Prevention Project-School Travel Planning Committee. (2016). Active transportation to support diabetes prevention: Expanding school health promotion programming in an Indigenous community. Evaluation and Program Planning, 56, 99-108. https://doi.org/10.1016/j.evalprogplan.2016.02.003

Matricciani, L., Olds, T., \& Petkov, J. (2012). In search of lost sleep: Secular trends in the sleep time of school-aged children and adolescents. Sleep Medicine Reviews, 16(3), 203-211. https://doi.org/10.1016/j.smrv.2011.03.005

McNeil, J., Doucet, E., \& Chaput, J.-P. (2013). Inadequate sleep as a contributor to obesity and Type 2 diabetes. Canadian Journal of Diabetes, 37(2), 103-108. https://doi.org/10.1016/j.jcjd.2013.02.060

Montour, L. T., \& Macaulay, A. C. (1985). High prevalence rates of diabetes mellitus and hypertension on a North American Indian reservation. CMAJ, 132(10), 1110-1112.

Moules, N. J., McCaffrey, G., Field, J. C., \& Laing, C. M. (2015). Conducting hermeneutic research: From philosophy to practice. New York, NY: Peter Lang.

Murdoch-Flowers, J., Tremblay, M.-C., Hovey, R., Delormier, T., Gray-Donald, K., Delaronde, E., \& Macaulay, A. C. (2017). Understanding how Indigenous culturally-based interventions can improve participants' health in Canada. Health Promotion International. Advance online publication. https://doi.org/10.1093/heapro/dax059

Owens, J. A., Spirito, A., \& McGuinn, M. (2000). The Children's Sleep Habits Questionnaire (CSHQ): Psychometric properties of a survey instrument for school-aged children. Sleep, 23(8), 1-9. https://doi.org/10.1093/sleep/23.8.1d

Reutrakul, S., \& Van Cauter, E. (2014). Interactions between sleep, circadian function, and glucose metabolism: Implications for risk and severity of diabetes. Annals of the New York Academy of Sciences, 1311(1), 151-173. https://doi.org/10.1111/nyas.12355

Salsberg, J., Macridis, S., Garcia Bengoechea, E., Macaulay, A. C., \& Moore, S. (2017). Engagement strategies that foster community self-determination in participatory research: Insider ownership through outsider championship. Family Practice, 34(3), 336-340.

https://doi.org/10.1093/fampra/cmx001

Seganathy, E. (2014). Identifying the sleep habits of Kanien 'kehá:ka elementary school children: Kahnawake Schools Diabetes Prevention Project (KSDPP) (Master's thesis). Retrieved from http://digitool.library.mcgill.ca/R/ 
Smith, J. A. (2007). Hermeneutics, human sciences and health: Linking theory and practice. International Journal of Qualitative Studies on Health and Well-being, 2(1), 3-11. https://doi.org/10.1080/17482620601016120

Taveras, E. M., Gillman, M. W., Pena, M.-M., Redline, S., \& Rifas-Shiman, S. L. (2014). Chronic sleep curtailment and adiposity. Pediatrics, 133(6), 1013-1022. https://doi.org/10.1542/peds.2013-3065

Truth and Reconciliation Commission of Canada. (2015). Honouring the truth, reconciling for the future: Summary of the final report of the Truth and Reconciliation Commission of Canada. Retrieved from http://www.trc.ca/websites/trcinstitution/File/2015/Findings/Exec_Summary_2015_05_31_web_o. pdf

United Nations. (2008). United Nations declaration on the rights of Indigenous Peoples. Retrieved from http://www.un.org/esa/socdev/unpfii/documents/DRIPS_en.pdf

Warzak, W. J., Evans, S., Floress, M. T., Gross, A. C., \& Stoolman, S. (2011). Caffeine consumption in young children. The Journal of Pediatrics, 158(3), 508-509.

https://doi.org/10.1016/j.jpeds.2010.11.022

Young, T. K., Reading, J., Elias, B., \& O’Neil, J. D. (2000). Type 2 diabetes mellitus in Canada's First Nations: Status of an epidemic in progress. CMAJ, 163(5), 561-566. Retrieved from: http://www.nlc-bnc.ca/eppp-archive/100/201/300/cdn_medical_association/cmaj/vol-163/issue5/0561.htm 